\title{
AMPA Receptor-Induced Local Brain-Derived Neurotrophic Factor Signaling Mediates Motor Recovery after Stroke
}

\author{
Andrew N. Clarkson, ${ }^{1}$ Justine J. Overman, ${ }^{1}$ Sheng Zhong, ${ }^{2}$ Rudolf Mueller, ${ }^{2}$ Gary Lynch, ${ }^{3,4}$ and S. Thomas Carmichael ${ }^{1}$ \\ ${ }^{1}$ Department of Neurology, David Geffen School of Medicine, University of California, Los Angeles, Los Angeles, California 90095, ${ }^{2}$ Cortex Pharmaceuticals, \\ Inc., Irvine, California 92618, and Departments of ${ }^{3}$ Psychiatry and Human Behavior and ${ }^{4}$ Anatomy and Neurobiology, University of California, Irvine, \\ Irvine, California 92697
}

Stroke is the leading cause of adult disability. Recovery after stroke shares similar molecular and cellular properties with learning and memory. A main component of learning-induced plasticity involves signaling through AMPA receptors (AMPARs). We systematically tested the role of AMPAR function in motor recovery in a mouse model of focal stroke. AMPAR function controls functional recovery beginning $5 \mathrm{~d}$ after the stroke. Positive allosteric modulators of AMPARs enhance recovery of limb control when administered after a delay from the stroke. Conversely, AMPAR antagonists impair motor recovery. The contributions of AMPARs to recovery are mediated by release of brain-derived neurotrophic factor (BDNF) in periinfarct cortex, as blocking local BDNF function in periinfarct cortex blocks AMPAR-mediated recovery and prevents the normal pattern of motor recovery. In contrast to a delayed AMPAR role in motor recovery, early administration of AMPAR agonists after stroke increases stroke damage. These findings indicate that the role of glutamate signaling through the AMPAR changes over time in stroke: early potentiation of AMPAR signaling worsens stroke damage, whereas later potentiation of the same signaling system improves functional recovery.

\section{Introduction}

Stroke produces significant neurological deficits. At chronic periods after stroke, only $60 \%$ of people achieve functional independence in simple activities of daily living (Dobkin, 2004). Although physical therapies in neurorehabilitation after stroke improve functional recovery (Dobkin, 2008), no drug treatments exist that promote poststroke recovery. Neurorehabilitation uses learning rules to guide therapy (Krakauer, 2006) and these poststroke therapies induce changes in functional brain mapping that closely parallel those seen with memory and learning paradigms (Bütefisch et al., 2006; Kelly et al., 2006). Cellular responses in learning and memory paradigms, such as dendritic remodeling (Brown et al., 2007) and long-term potentiation (LTP) (Hagemann et al., 1998), are also active in experimental stroke studies. In addition, drugs that modulate cortical excitability, such as those that dampen tonic GABA inhibition, not only play a key role in modulating learning and memory responses but also play

Received Nov. 3, 2010; revised Dec. 11, 2010; accepted Jan. 14, 2011.

This work was supported by The Dr. Miriam and Sheldon G. Adelson Medical Research Foundation and The Larry L. Hillblom Foundation (S.T.C.). We thank Cortex Pharmaceuticals, Inc., for generously providing the ampakine compounds. This manuscript was completed partially during tenure of an American Heart Association Postdoctoral Fellowship, a Repatriation Fellowship from the New Zealand Neurological Foundation, and The Sir Charles Hercus Fellowship from the Health Research Council of New Zealand (A.N.C.). We thank Sarah Maclsaac for assistance in performing Western blot studies.

G.L. is a consultant for and has financial interests in Cortex Pharmaceuticals, Inc., which provided the ampakine used in this study. S.Z. and R.M. are employees at Cortex Pharmaceuticals, Inc.

Correspondence should be addressed to Dr. S. Thomas Carmichael at the above address. E-mail: scarmichael@mednet.ucla.edu.

A. N. Clarkson's present address: Departments of Psychology and Anatomy and Structural Biology, University of Otago, P.0. Box 913, Dunedin 9013, New Zealand.

DOI:10.1523/JNEUROSCI.5780-10.2011

Copyright $\odot 2011$ the authors $\quad 0270-6474 / 11 / 313766-10 \$ 15.00 / 0$ a role in stroke recovery (Clarkson et al., 2010). Given these similarities, molecular systems associated with learning and memory may underpin recovery from stroke.

Studies of molecular memory systems suggest specific targets for a pharmacological learning therapy in stroke. AMPA receptors (AMPARs) play a key role in cellular mechanisms of learning and memory. Changes in AMPAR trafficking and number underlie elements of LTP and long-term depression (Lynch et al., 2008). AMPAR activation also induces brainderived neurotrophic factor (BDNF) (Jourdi et al., 2009), a neurotrophin that is essential for neuronal remodeling and LTP (Bramham, 2008). Drugs that positively modulate glutamate-induced AMPAR-gated synaptic currents, such as "ampakines," potentiate excitatory signaling and enhance learning and memory in both animals (Hampson et al., 1998; Rex et al., 2006) and humans (Goff et al., 2008). These drugs not only promote LTP, but a subset of ampakines also induces BDNF levels in an activity-dependent manner (Lauterborn et al., 2003; Rex et al., 2006). These are termed high-impact, or type II, ampakines (Arai and Kessler, 2007). The role of enhanced AMPAR signaling, with its attendant effect on BDNF, has not been studied in stroke recovery.

We systematically tested the role of AMPAR signaling in stroke recovery using pharmacological gain- and loss-offunction studies. The results indicate that a delayed enhancement in AMPA signaling promotes behavioral recovery after stroke, whereas blocking AMPAR signaling during the same period retards recovery. This recovery effect is mediated via induced BDNF activity within the periinfarct cortex. In contrast to this delayed recovery effect, early enhancement of AMPA signaling increases infarct size. These findings consti- 
tute the first evidence that an inflection point from harm to benefit exists within the first week after stroke for AMPAR function, localizes the effect of AMPAR signaling in functional recovery to the periinfarct tissue that surrounds the stroke, and suggests that pharmacological treatments that enhance AMPAR signaling during the period of recovery after stroke may provide a neural repair therapy.

\section{Materials and Methods}

Photothrombosis

Focal stroke was induced by photothrombosis in adult male C57BL/6 mice weighing 20-25 g as previously described (Clarkson et al., 2010).

\section{In vivo drug dosing}

CX1837 (0.33 and $1 \mathrm{mg} / \mathrm{kg}$ ) and CX1739 (3 and $30 \mathrm{mg} / \mathrm{kg}$ ) were dissolved in $30 \%$ hydroxypropyl $\beta$-cyclodextran (HPCD) (made 1:1 in $0.9 \%$ saline and distilled $\mathrm{H}_{2} \mathrm{O}$ ) and administered intraperitoneally twice daily starting $5 \mathrm{~d}$ after stroke for a period of 6 weeks. The AMPAR antagonist CFM2 $(50 \mu \mathrm{m} / \mathrm{kg}$ ) (De Sarro et al., 1999) was administered intraperitoneally twice daily for 6 weeks.

A hyaluronan/heparan sulfate proteoglycan biopolymer hydrogel (Extracel-HP; Glycosan) was used to locally deliver TrkB-Fc $(5 \mu \mathrm{g} / \mathrm{ml})$ and human IgG-Fc (antibody and vehicle control) to the periinfarct cortex (Li et al., 2010). This hydrogel was chosen because it is composed of naturally occurring brain extracellular matrix constituents; remains liquid for a period after mixing so that it can be injected into the brain through a small, minimally invasive needle; and will gel within the stroke cavity, conforming to the boundaries of this cavity. We have shown that this hydrogel releases small and large proteins for up to 4 weeks from the infarct cavity after stroke (Li et al., 2010). Five days after stroke, $10 \mu \mathrm{l}$ of Extracel-HP, impregnated with TrkB-Fc ( $5 \mu \mathrm{g} /$ $\mathrm{ml}$ ) or human IgG-Fc (vehicle), was injected directly into the stroke infarct cavity using a 30 gauge needle attached to a Hamilton syringe. Extracel-HP was prepared according to the manufacturer's instructions. The antibody or antibody conjugate was added to Heprasil (component 1 of hydrogel), followed by addition of Extracel (component 2 of hydrogel) in a 4:1 ratio. Extracel-HP impregnated with antibody was injected immediately after preparation into the stroke cavity at stereotaxic coordinates $0 \mathrm{~mm}$ anteroposterior (AP), $1.5 \mathrm{~mm}$ mediolateral (ML), and $0.75 \mathrm{~mm}$ dorsoventral (DV). In vitro studies indicate that, at $37^{\circ} \mathrm{C}$ in an aqueous environment, the liquid constituents form a gel within $20 \mathrm{~min}$. The TrkB-Fc-impregnated biopolymer hydrogel was administered alone and in concert with twice daily intraperitoneal administration of CX1837 ( $1 \mathrm{mg} / \mathrm{kg})$ starting from $5 \mathrm{~d}$ after stroke for 6 weeks.

\section{Behavioral assessment}

Animals were tested once on both the grid-walking and cylinder tasks, 1 week before surgery to establish baseline performance levels. For the reaching task, mice were trained for a period of $14 \mathrm{~d}$ and subsequently tested on day 15 to establish a baseline reading. For all of the studies, animals were tested on weeks 1,2, 4, and 6 after stroke at approximately the same time each day at the end of their dark cycle. Behaviors were scored by observers who were blind to the treatment group of the animals in the study as previously described (Clarkson et al., 2010).

Grid-walking and spontaneous-forelimb (cylinder) task. Both gridwalking and cylinder tasks were performed as previously described (Clarkson et al., 2010).

Single-pellet skilled-reaching task. For loss-of-function studies assessing CFM2, the single-pellet skilled-reaching task was used (Conner et al., 2005). Before stroke, animals were trained for 3 weeks to successfully reach and retrieve $20 \mathrm{mg}$ sugar pellets (Bio-Serv). A three lane Plexiglas reaching apparatus $(30 \mathrm{~cm}$ deep, $10 \mathrm{~cm}$ wide, and $30 \mathrm{~cm}$ high for each lane) was constructed to allow simultaneous recording of three animals. Each lane consists of two $5 \mathrm{~mm}$ slots situated against the front-right and front-left walls of the chamber to force the mouse the reach for the pellets using either their right or left forepaws. A 5 -mm-thick plastic shelf was mounted $15 \mathrm{~mm}$ from the floor at the front of the box.
During the training period, mice were fasted to $90 \%$ of their body weight and maintained at this level for the full 3 week training period. Animals were habituated during the first week by placing them into the lanes two times for $7.5 \mathrm{~min}$ each time with a $5 \mathrm{~min}$ recovery period in their home cage. Sugar pellets were freely available on the lane floor within tongue reach as well as just outside the slot opening. Pellets were gradually removed from the floor until only the pellets just outside of slot remained and the mice were forced to retrieve the pellets. The second 2 weeks consisted of training the mice one time for $15 \mathrm{~min}$ to retrieve 15 pellets through the slot. Pellets were gradually moved further away from the slot ( $\sim 1 \mathrm{~cm}$ maximal distance) to force the mice to use their paw and not their tongue.

Reaching success. All mice were fasted the night before testing. Pellets were presented one at a time and reaches were recorded with a Canon VIXIA HV30 video recorder. Each animal was presented with a total of 15 pellets during each $15 \mathrm{~min}$ test period. If an animal reached through the slot and obtained/grasped a food pellet and brought the pellet back through the slot, the reach was scored as a success. If an animal knocked the pellet away or dropped the pellet after grasping it, the reach was scored as a miss. The performance of each mouse was scored as follows: percentage success $-\left(\right.$ number of successful retrievals/15) ${ }^{\star} 100$.

\section{$B D A$ injection and infarct size}

Eight week poststroke animals were injected with the neuroanatomical tracer $10 \%$ biotinylated dextran amine (300 $\mathrm{nl}$ of BDA; 10,000 MW; Invitrogen). BDA was pressure injected into the forelimb motor cortex (AP, 1.5; ML, 1.75; DV, 0.75) using a picospritzer with pulled glass micropipettes (tip diameter, 15-20 $\mu \mathrm{m}$ ), using previously described stereotaxic techniques (Carmichael et al., 2001). Seven days after BDA injection, animals were perfused with 0.1 м PBS followed by $4 \%$ paraformaldehyde. The cortex was removed from the subcortical tissue and flattened precisely between two glass slides separated by $2 \mathrm{~mm}$ steel washers to ensure equivalent cortical thickness across subjects. Tangential cortical sections $(40 \mu \mathrm{m})$ were generated using a sliding microtome and stored in cryoprotectant at $-20^{\circ} \mathrm{C}$. Tangential cortical sections were removed from cryoprotectant and rinsed in $0.1 \mathrm{M} \mathrm{KPBS}$. Sections were processed for cytochrome oxidase histochemistry to visualize the somatosensory body map. BDA was visualized in the same sections using the Standard Vectastain Elite kit (Vector Laboratories) and the chromagen DAB, enhanced with cobalt chloride (Carmichael et al., 2001; Li et al., 2010). Sections were mounted on subbed slides, dehydrated in ascending alcohols, cleared in xylenes, and coverslipped. The distribution of BDA-labeled cell bodies and axons were plotted in tangential sections graphed on scatter plots overlaid on physical maps through the barrel field of the cortex (Carmichael et al., 2001; Li et al., 2010). For the histological assessment of infarct size, brains were processed $7 \mathrm{~d}$ after stroke using cresyl violet as previously described (Ohab et al., 2006; Clarkson et al., 2010).

Stereological quantification of axonal sprouting. The BDA injection volume was measured by calculating the average injection core volume for each treatment group. The average BDA injection area in each section, determined by outlining the limit of extracellular tracer deposition, was multiplied by the sum of the thickness of the section and then summed for all sections in the series. Anterior/posterior and medial/lateral BDA injection location was analyzed by measuring the distance from the center of the injection site to the rostral edge of the tissue and the midline of the cortex, respectively (Li et al., 2010). The size and location of each BDA injection did not vary significantly across animals or by treatment condition (see Fig. 8).

Sprouting was quantified by digitally marking each BDA-positive cell in the superficial layers of the cortex (layers 2/3) from each group with a digitizing microscope/computer-controlled motorized stage system (Leica Microsystems; Ludl Electronic Products) and interfaced camera (MicroFire) with a neuroanatomical analysis program (MicroBrightField). BDA-positive cells were marked in $x / y$ coordinates relative to the center of the injection site by an observer blind to the treatment conditions. The hardware provides a labeling precision of $\pm 5 \mu \mathrm{m}$ in mapping the location of all BDA cells within the tangential cortical sections. This process generates an $x / y$ plot of the location of all labeled cells in each 
brain section. The $x / y$ plots of each brain from each experimental group were registered with respect to the injection site and coregistered with functionally relevant anatomical regions, produced by the staining of the mouse somatosensory body map in cytochrome oxidase, to generate a composite axonal map for each treatment condition (Carmichael et al., 2001; Li et al., 2010). Custom software was developed to produce quantitative connectional maps that consist of pixels, with the number of axons in each pixel mapped in register with anatomical brain structures. Polar plots representing these circular data illustrate both location and direction of sprouting. Polygons represent the 70th percentile of the distances of BDA-labeled axons from the injection site in each segment of the graph. Weighted polar vectors represent the median vector multiplied by the median of the normal distribution of the number of points in a given segment of the graph. The normal distribution is the axonal projection pattern that would occur if neurons projected equally and radially from the injection site. These maps were then analyzed for statistically significant differences in connectional profiles between groups.

Statistical analysis of axonal sprouting. For quantitative connectional maps, two statistical analysis paradigms were used to determine significant differences. First, scatter plots were analyzed using Hotelling's $T^{2}$ test for spatial correlation. For data with a common covariance matrix, such as the map of BDA-labeled cell bodies in tangential cortical sections, Hotelling's $T^{2}$ method tests the hypothesis of multivariate mean equality: that the means for the set outcome variable (axonal location for each animal, averaged by experimental condition) are equivalent across groups. The $T^{2}$ statistic is the analog of Student's two-group $t$ statistic for testing equality of group means for a single outcome variable. Values of $p$ were computed without Gaussian assumptions via a bootstrap method, with 1000 resamplings. Values of $p$ represent the ridge estimate of (log) Hotelling's $T^{2}$ for the comparison between two groups. A mask with a radius of $500 \mu \mathrm{m}$ was applied around the injection site to account for the uniformity of the injection site itself and immediately adjacent BDA labeling across groups, regardless of sprouting pattern. A second analysis tool tested for significant differences by location within the cortical hemisphere. This approach uses the polar distribution of projection patterns across treatment groups. For each treatment condition, the $x / y$ coordinate of every BDA-positive cell body was converted to an equivalent polar coordinate relative to the injection site as center (Carmichael et al., 2001; Dancause et al., 2005; Ohab et al., 2006) $(r, \theta)$. The location of each cell body was transferred to common polar space and a mean projection vector was computed for each treatment group. The projection vector was defined by the angle of projection from the injection site $(\theta)$ and distance (length of vector, $r$ ) from the center of the injection site (forelimb motor cortex).

\section{ELISA and immunoblotting analysis}

Tissue was collected from around the stroke site from stroke plus vehicle, stroke plus CX1837 (1 mg/kg), and stroke plus CX1739 (3 mg/kg), and control groups $7 \mathrm{~d}$ after stroke. Cortical tissue was dissected in a $1 \mathrm{~mm}$ radius around the stroke infarct core, including the core itself, and flash frozen on dry ice.

Equal volumes of tissue were homogenized in $100 \mathrm{ml}$ of homogenization buffer [Complete Protease Inhibitor Tablet (Invitrogen), 1 mm phenylmethylsulfonylfluoride, 50 mм Tris-HCl, 5 mм EDTA, 10 mм EGTA, $1 \%$ Triton X-100] for $\sim 1 \mathrm{~min}$. Tissue and homogenization buffer were incubated on ice for $30 \mathrm{~min}$, followed by a $5 \mathrm{~min}$ spin at $14,000 \mathrm{rpm}$. The supernatant was collected and total protein concentrations were determined using the DC Protein Assay (Bio-Rad). BDNF was measured using the BDNF ELISA Emax Immunoassay System (Promega) as per the manufacturer's instructions. BDNF levels were determined relative to a standard curve constructed from measures of kit-supplied BDNF protein standards ( $0-500 \mathrm{pg}$ of BDNF protein) that were assayed simultaneously with the experimental samples. BDNF levels are expressed as picograms of BDNF per $100 \mu \mathrm{g}$ of sample protein.

For immunoblotting experiments, protein $(10 \mu \mathrm{g})$ was loaded onto a $12 \%$ SDS-polyacrylamide gel, subjected to electrophoresis, and transferred to a pure nitrocellulose membrane (GE Healthcare). The membrane was blocked in $10 \%$ nonfat milk and probed with polyclonal antibodies specific for anti-TrkB (1:1000; Santa Cruz Biotechnology) and anti-p-Trk (1:5000; Santa Cruz Biotechnology). The blots were incubated with peroxidase-labeled anti-rabbit IgG (1:2000; Vector Laboratories) and immunoreactive proteins were visualized using enhanced chemiluminescence (GE Healthcare). $\beta$-Actin was used as a loading control (1:5000; Abcam). Optical density (OD) was determined using the NIH ImageJ software. Pixel intensities were converted to OD using the calibration curve of the software, and background-subtracted values were expressed as OD/100 g total protein.

\section{In vivo electrophysiological recordings}

Male Long-Evans rats (250-350 g) were anesthetized by pentobarbital $(60 \mathrm{mg} / \mathrm{kg}$, i.p.) and maintained under anesthesia by pentobarbital infusion $\left(2-4 \mathrm{mg} \cdot \mathrm{kg}^{-1} \cdot \mathrm{h}^{-1}\right)$. Under anesthesia, animals were placed in a stereotaxic frame and small holes were drilled into the skull of the left hemisphere to allow the positioning of a stimulating electrode ( -7.8 to $-8.1 \mathrm{AP} ; 4.2$ to $4.4 \mathrm{ML})$ and a recording electrode $(-3.0$ to $-3.3 \mathrm{AP} ; 1.6$ to $2.2 \mathrm{ML})$. A monopolar stainless-steel stimulating electrode $(175 \mu \mathrm{m}$, insulated with Formvar) was lowered into the perforant path together with a platinum/iridium recording electrode $(75 \mu \mathrm{m})$ into the hilus of the dentate gyrus of the hippocampus. The current used to elicit an evoked potential was adjusted to produce a response size $50-60 \%$ of the maximal spike-free amplitude. Evoked hilar EPSPs were recorded in response to single-pulse stimulation delivered at a frequency of one pulse per $20 \mathrm{~s}$. After 20-30 min of stable baseline recordings, CX1837 or CX1739 in 33\% HPCD were injected intraperitoneally and field potentials recorded continuously every $20 \mathrm{~s}$ for an additional $80-100$ min (see Fig. 3).

Data acquisition and analysis was performed using commercially available software (NAC and NACSHOW). The amplitude, half-width, and area of the EPSPs were measured for each stimulation pulse, and the effects of CX1837 on EPSPs were compared with baseline EPSPs using a two-tailed, two-sample equal-variance Student $t$ test.

\section{Statistical analysis}

All data are expressed as mean \pm SEM. For behavioral testing, differences between treatment groups were analyzed using two-way ANOVA with repeated-measures and Newman-Keuls' multiple pairwise comparisons for post hoc comparisons. BDA projection profiles between controls and experimental groups were analyzed using Hotelling's $t$ test (Carmichael et al., 2001; Li et al., 2010). The level of significance was set at $p<0.05$. Samples sizes for all the experiments were as follows: $n=8-10$ per group for behavior; $n=4$ per group for histology, BDA quantification, and immunoblotting; and $n=4$ per group for in vivo electrophysiology.

\section{Results}

\section{Positive modulators of AMPAR signaling improve motor recovery after stroke}

Mice were given a stroke in forelimb motor cortex and received behavioral testing of forelimb and hindlimb motor function for 6 weeks after stroke. Stroke causes mice to exhibit limb use deficits for at least 6 weeks after the infarct, with mice still exhibiting 55\% impairment in forelimb function on the grid walk and $65 \%$ on the cylinder task. Mice have an increase in the number of footfaults (both right-forelimb and hindlimb) on a grid walk task, and an increased use of the ipsilateral forelimb to the stroke in spontaneous use on the cylinder task (Fig. 1).

To test the effect of AMPAR signaling in motor recovery after stroke with an in vivo gain-of-function assay, we administered both BDNF-inducing (CX1837) and non-BDNF-inducing (CX1739) ampakines beginning $5 \mathrm{~d}$ after stroke, a time in which most cell death is complete (Braun et al., 1996; Lipton, 1999; Ohab et al., 2006). Both classes of ampakines promote an increase in ionotropic conductance in response to glutamate binding to the AMPAR, whereas only CX1837 promotes an elevation in BDNF levels (Lauterborn et al., 2003, 2009; Simmons et al., 2009). CX1837 and CX1739 both cross the blood-brain barrier (BBB) 
A

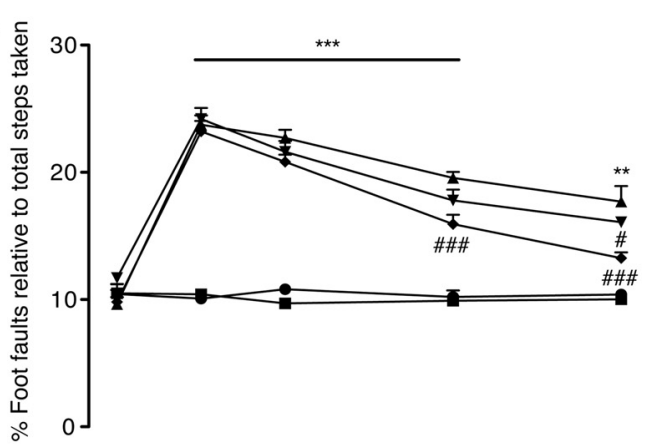

B

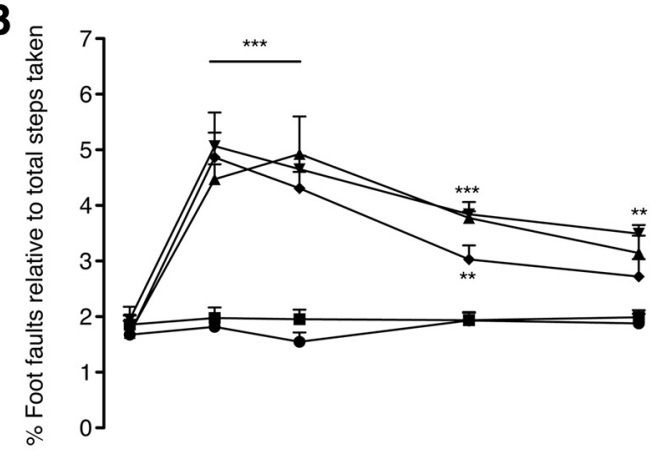

C

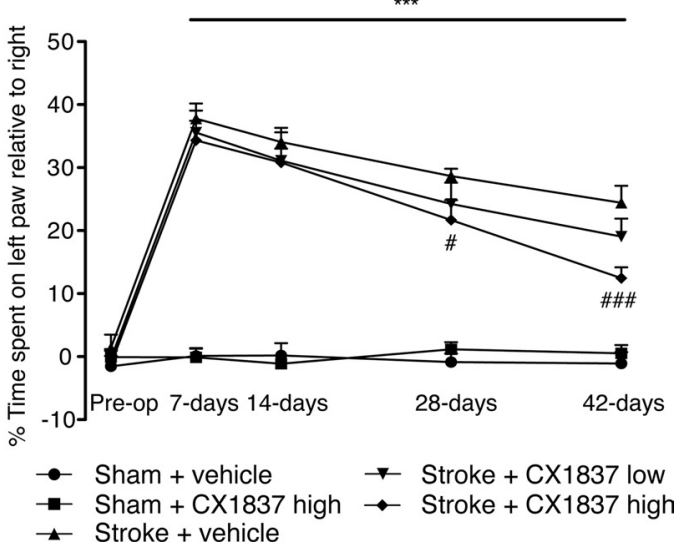

Figure 1. Behavioral recovery in the presence of the high-impact ampakine, $X X 1837$. Behavioral recovery after stroke was assessed on grid-walking $(\boldsymbol{A}, \boldsymbol{B})$ and cylinder/forelimb asymmetry $(\boldsymbol{C})$ tasks. Analysis of forelimb $(\boldsymbol{A})$ and hindlimb $(\boldsymbol{B})$ footfaults revealed a significant increase in the number of footfaults compared with baseline and time-matched sham-treated controls. Administration of CX1837 $(0.33$ or $1 \mathrm{mg} / \mathrm{kg})$ resulted in a gradual yet steady dose-dependent decrease in the number of footfaults compared with vehicle (30\% HPCD)-treated stroke animals. Assessment of forelimb asymmetry using the cylinder task ( $C$ ) showed that the mice had a greater tendency to spend more time on their left forepaw poststroke as revealed by an increase in the left/right ratio. Treatment with CX1837 resulted in a steady dose-dependent gain of function of the right forelimb. Data are shown as mean \pm SEM for $n=8$ per group. ${ }^{* *} p<0.01,{ }^{* * *} p<0.001$ compared with sham controls; ${ }^{\#} p<0.05,{ }^{\# \#} p<0.001$ compared with stroke plus vehicle-treated animals.

when given systemically and activate excitatory signaling (see Fig. 3). CX1837 (0.33 or $1 \mathrm{mg} / \mathrm{kg}$, i.p., bid) promotes a dosedependent gain of function in the impaired forelimb (Fig. $1 A, C$ ), from week 4 after stroke onward, with only a mild impairment still evident by week 6 after stroke (Fig. $1 A, C$ ). Animals treated with CX1837 also showed a mild gain of function with the right hindlimb (Fig. $1 B$ ).

Treatment with CX1739 for 6 weeks resulted in a small decrease in the number of footfaults on the grid-walking task and a small increase in the use of the right-impaired forelimb on the cylinder task (Fig. 2). However, these changes after CX1739 treat-
A
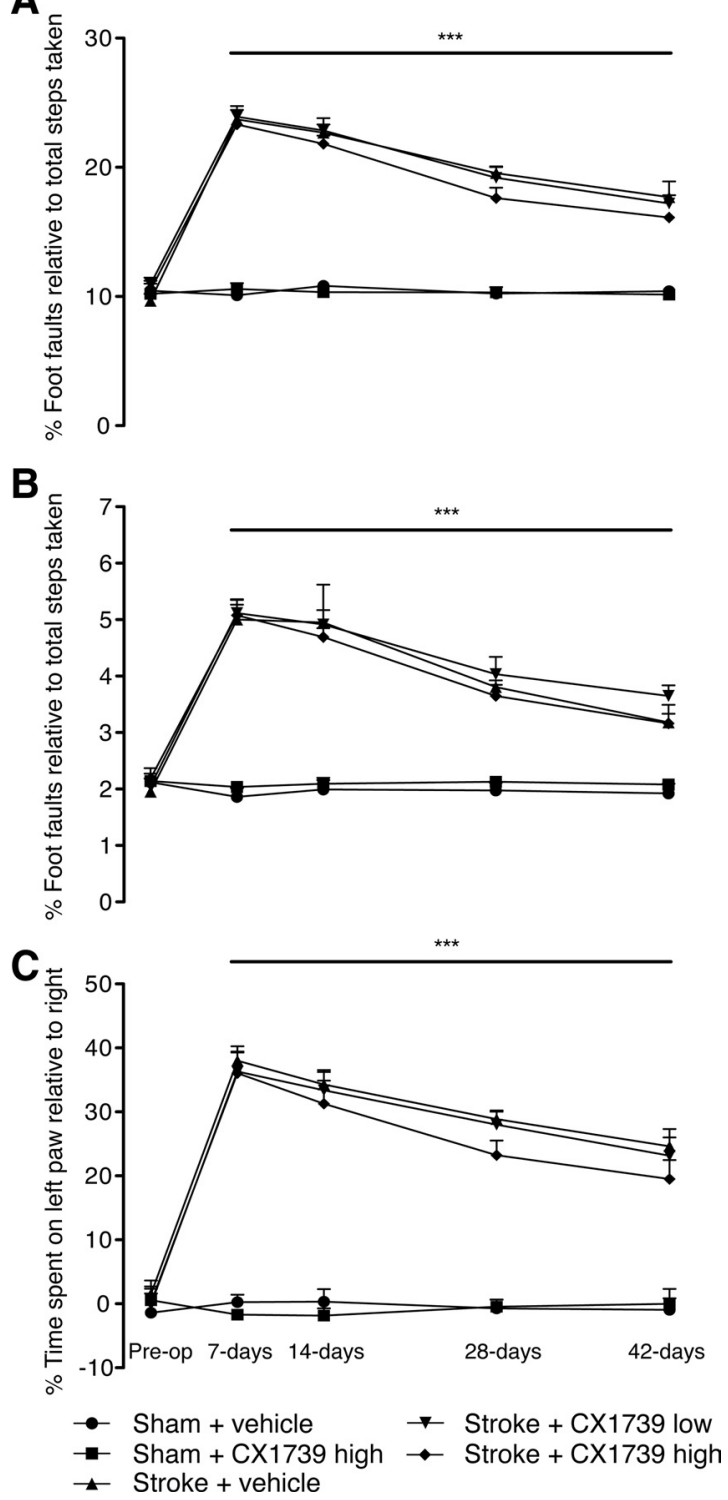

Figure 2. Behavioral recovery in the presence of the low-impact ampakine, CX1739. Behavioral recovery after stroke was assessed on grid-walking $(\boldsymbol{A}, \boldsymbol{B})$ and cylinder/forelimb asymmetry $(\boldsymbol{C})$ tasks. Analysis of forelimb $(\boldsymbol{A})$ and hindlimb $(\boldsymbol{B})$ footfaults revealed a significant increase in the number of footfaults compared with baseline and time-matched sham-treated controls. Administration of $C X 1739$ ( 3 or $30 \mathrm{mg} / \mathrm{kg}$ ) resulted in a small yet nonsignificant decrease in the number of footfaults compared with vehicle-treated stroke animals. Assessment of forelimb asymmetry using the cylinder task $(\boldsymbol{C})$ revealed that treatment with CX1739 did not result in a decrease in the left/ratio and were similar to stroke plus vehicle-treated controls. Data are shown as mean \pm SEM for $n=8$ per group. ${ }^{* * *} p<0.001$ compared with sham controls.

ment were not significantly ( $p=0.054)$ different from stroke plus vehicle-treated controls at either low or high doses ( 3 or 30 $\mathrm{mg} / \mathrm{kg}$, i.p., bid).

\section{CX1837 and CX1739 freely cross the BBB to have a synaptic effect}

To assess whether these compounds crossed the BBB and were having an effect synaptically, EPSPs were recorded from anesthetized animals in vivo. CX1837 $(0.2-10 \mathrm{mg} / \mathrm{kg}$, i.p.) resulted in an immediate and dose-dependent increase in EPSP amplitude (Fig. 3). Administration of CX1739 (5-20 mg/kg, i.p.) resulted in a similar immediate increase in EPSP amplitude. However, unlike 
CX1837, the effect was much less, with an excitability ceiling seen after $10 \mathrm{mg} / \mathrm{kg}$ (Fig. 3).

AMPA gain of function is attenuated in the presence of BDNF blockade

A BDNF-inducing ampakine such as CX1837 may promote motor recovery after stroke because of potentiation of inward cation influx and excitatory signaling after stroke, or via the enhancement of BDNF expression. Furthermore, as CX1837 is administered systemically and freely penetrates the BBB (Fig. 3), the locus within the brain responsible for the regulation of motor recovery after stroke remains unknown. To help delineate a BNDF effect versus an activity-dependent AMPAR-mediated effect, we first measured the induction of BDNF and activation of its tyrosine kinase receptor, TrkB, in stroke alone and after CX1837 treatment. To further isolate the locus of BDNF signaling, local periinfarct BDNF blockade was performed in stroke and in the CX1837 treatment groups.

BDNF signals via activation and phosphorylation of its TrkB receptor. Studies have previously reported a positive correlation between ampakine-mediated BDNF expression and phosphorylation of TrkB (Jourdi et al., 2009; Lauterborn et al., 2009). Stroke and CX1837 significantly induce BDNF and BDNF signaling. Stroke induced BDNF in periinfarct cortex compared with control cortex at $7 \mathrm{~d}$ after stroke $(p<0.05)$ (Fig. 4A). Treatment with CX1837 resulted in an additional increase in BDNF levels compared with stroke plus vehicle-treated controls $(p<0.001)$. However, treatment with CX1739 did not change the level of BDNF expression compared with stroke plus vehicle-treated animals. There were no significant differences in BDNF levels in the contralateral hemisphere in any stroke or treatment groups (Fig. $4 B$ ). In periinfarct cortex, there is a small increase in TrkB phosphorylation in stroke alone compared with control samples. Stroke plus CX1837, however, resulted in a marked increase in TrkB phosphorylation $(p<$ $0.01)$. CX1739 did not change the level of TrkB phosphorylation compared with stroke plus vehicle-treated animals (Fig. 4C,E). No differences in TrkB phosphorylation were observed on the contralateral hemisphere (Fig. 4D,F). These data indicate that BDNF activity and an AMPAR stimulating effect is present only in periinfarct cortex during recovery. Stroke induces an increase in BDNF only in periinfarct cortex. CX1837 enhances this periinfarct BDNF induction and produces a significant activation of its receptor.

To determine a behavioral role for normal and CX1837induced BDNF after stroke, the BDNF receptor decoy, TrkB-Fc, was locally delivered into periinfarct cortex in the presence and absence of systemically administered CX1837 (1 mg/kg, i.p., bid) beginning $5 \mathrm{~d}$ after stroke. Local periinfarct treatment with the TrkB-Fc receptor decoy completely blocked the CX1837mediated behavioral gain of function (Fig. 5). However, the functional recovery in stroke animals treated with CX1837 (1 $\mathrm{mg} / \mathrm{kg}$ ) in the presence of IgG-Fc control was not blocked.
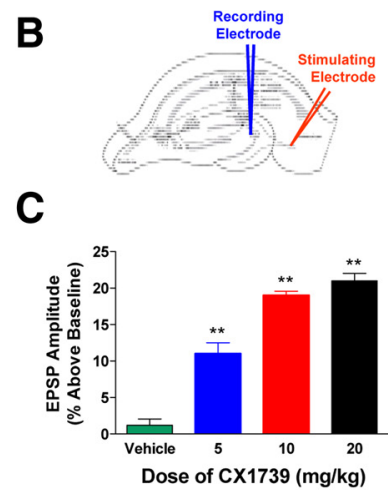

E

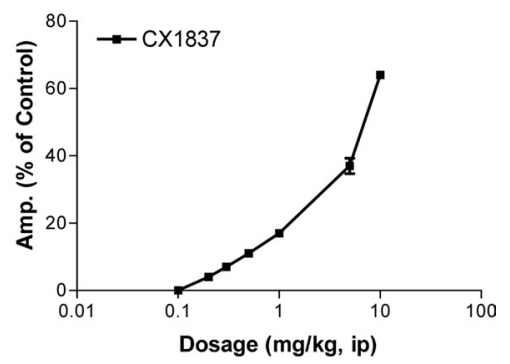

Stroke animals treated with TrkB-Fc alone showed a small decrease in the rate of normal stroke-induced recovery. These findings indicate that the CX1837 induction of BDNF signaling within the periinfarct cortex mediates motor recovery after stroke.

\section{Blockade of AMPA signaling impairs motor recovery after stroke}

Boosting AMPAR-mediated BDNF signaling in periinfarct cortex promotes motor recovery after stroke in this mouse model. If AMPAR signaling is indeed necessary for motor recovery after stroke, then blocking AMPAR signaling starting $5 \mathrm{~d}$ after stroke should impair motor recovery. CFM2, a blood-brain barrierpermeable AMPAR antagonist (De Sarro et al., 1999), was administered ( $50 \mu \mathrm{mol} / \mathrm{kg}$, i.p., bid) for 6 weeks starting $5 \mathrm{~d}$ after stroke. Treatment of CFM2 did not produce general behavioral side effects, such as reduced motor activity, impaired grooming, or weight loss (De Sarro et al., 1999). CFM2 administration results in a significant impairment in the normal gain of motor function after stroke as assessed by normal forelimb movement (Fig. 6A,C). To further test the behavioral effects of AMPAR signaling, we tested AMPAR blockade on a task that normally recovers after stroke, a skilled-reaching behavior. The ability to retrieve food pellets successfully through a small opening using the impaired right forelimb was significantly decreased only at the 1 week time point in normal stroke (Fig. 6D). Treatment with CFM2 impaired this early recovery, as shown by a significant impairment in the ability to retrieve pellets successfully out to 2 weeks after stroke (Fig. 6D). 


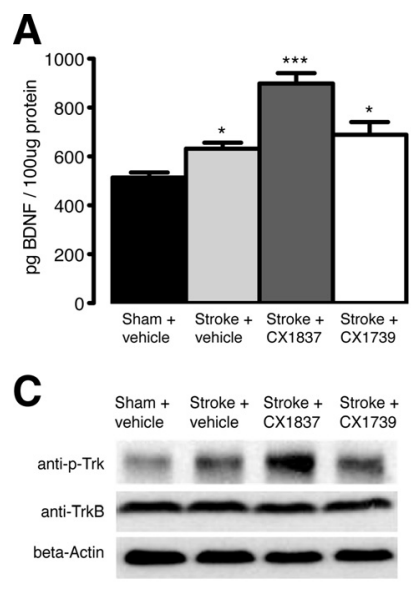

E

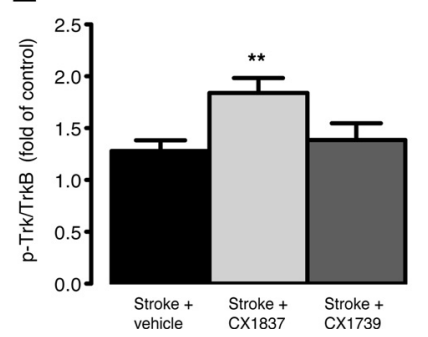

B

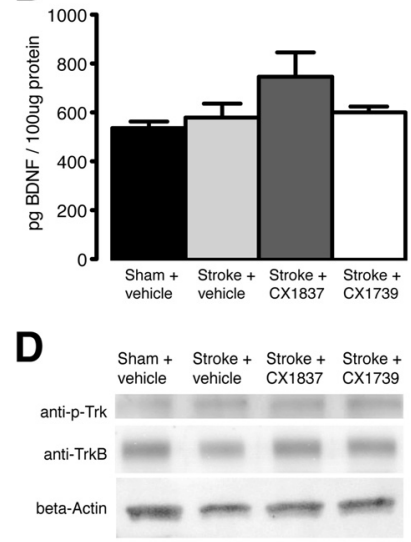

$\mathbf{F}$

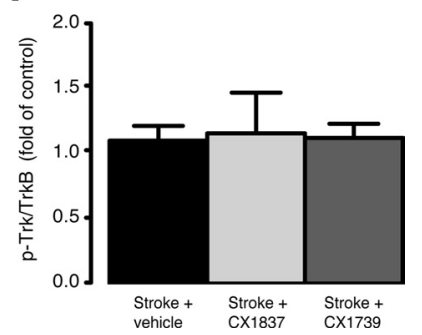

Figure 4. Ampakine-mediated alterations in BDNF expression. CX1837 mediates BDNF release within the periinfarct cortex poststroke. BDNF expression levels $(\boldsymbol{A})$ were elevated $7 \mathrm{~d}$ after stroke. Treatment with CX1837 from day 5 after stroke resulted in a significant increase in BDNF levels, whereas CX1739 did not alter the level of BDNF expression compared with stroke control. No significant changes in BDNF levels were observed on the contralateral hemisphere $(\boldsymbol{B})$. Assessment of BDNF receptor activation TrkB/p-Trk showed a significant increase in activation after X1837 treatment within the periinfarct cortex poststroke ( $\boldsymbol{C}, \boldsymbol{E})$. Assessment of TrkB/p-Trk in the contralateral hemisphere showed no changes between treatment groups $(\boldsymbol{D}, \boldsymbol{F})$. Data are shown as mean \pm SEM for $n=4$ per group. ${ }^{*} p<0.05,{ }^{* *} p<0.01,{ }^{* * *} p<0.001$ compared with sham controls.

Positive AMPAR modulation does not alter poststroke axonal sprouting

The process of neural repair after stroke involves sprouting of new connections within the periinfarct cortex (Carmichael et al., 2001; Li et al., 2010). BDNF has its locus of action in periinfarct cortex (Figs. 4, 5) and has been shown to have significant effects on neuronal sprouting (Batchelor et al., 2008). To assess whether the functional gains associated with CX1837-induced BDNF are linked to sprouting of new connections within the periinfarct region, we quantitatively mapped the motor cortex connections (Li et al., 2010) in stroke plus vehicle controls and stroke plus CX1837 treatment at the maximally effective dosing regimen (1 $\mathrm{mg} / \mathrm{kg}$, i.p., bid). The distribution of BDA-labeled cell bodies were mapped in $x / y$ coordinates, registered to the somatosensory body map in tangential cortical sections, collapsed from individual animals to treatment groups, and statistically compared for changes in the pattern of motor cortex connections (Fig. 7). There was no significant difference in the pattern of motor system cortical connections between stroke-control and stroke plus CX1837 (Fig. 8).

\section{Inflection point in AMPA effects on stroke size}

Glutamate-induced excitotoxicity mediates early cell death after stroke (Lipton, 1999). Previous studies using AMPAR antagonists (Weiser, 2005) have shown a decrease in stroke size in animals when treatments have started at the time of or shortly after

A

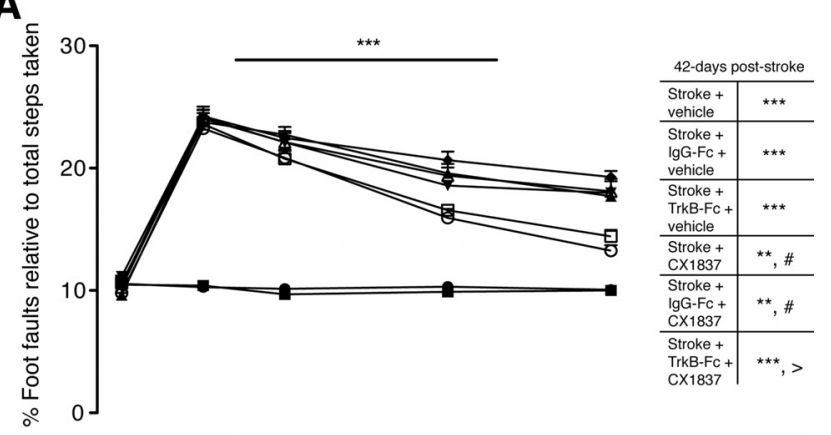

B
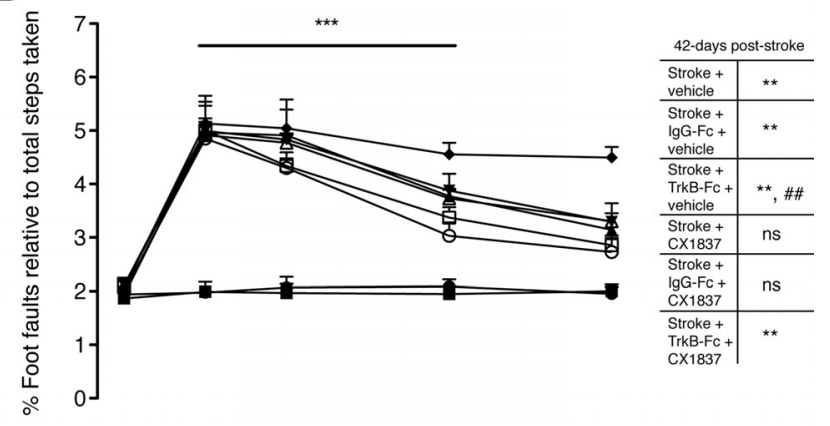

C

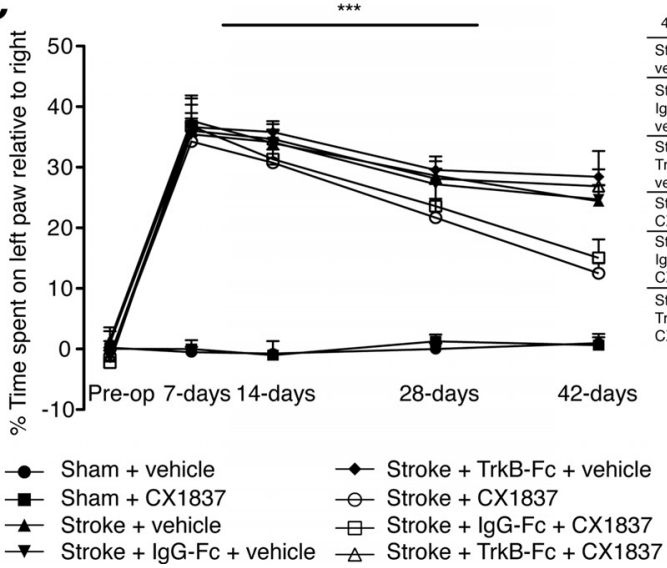

42-days post-stroke \begin{tabular}{c|c}
$\begin{array}{c}\text { Stroke }+ \\
\text { vehicle }\end{array}$ & $\star \star \star$ \\
\hline
\end{tabular} \begin{tabular}{c|c} 
Stroke + \\
IgG-Fc + \\
\hline
\end{tabular} vehicle Stroke + + TrkB-Fc+ vehicle \begin{tabular}{l|l} 
Stroke + & ** \# \\
CX1837 & \# \\
\hline Stoke &
\end{tabular} Stroke + \begin{tabular}{l|l} 
CX1837 & $* *$ \\
\hline Stroke + &
\end{tabular} TrkB-Fc+
$\mathrm{CX} 1837$

gure 5. The BDNF ligand decoy, TrkB- $F c$, negates the $X X 1837$-mediated gain of behavioral function. BDNF blockade within the periinfarct cortex was achieved by infusing TrkB-Fcimpregnated hydrogel into the stroke cavity. Behavioral recovery was assessed after CX1837 treatment in the presence and absence of TrkB-Fc on grid-walking $(\boldsymbol{A}, \boldsymbol{B})$ and cylinder/forelimb asymmetry $(\boldsymbol{C})$ tasks. Implantation of the TrkB-Fc-impregnated hydrogel on day 5 after stroke resulted in a complete blockade of the CX1837-mediated gain of behavioral function on both the grid-walking and cylinder task. Furthermore, vehicle-treated stroke animals that received the TrkB-Fc hydrogel showed impairment in the normal gain of behavioral recovery for hindlimb footfaults $(\boldsymbol{B})$. These results show a requirement for local periinfarct BDNF levels in facilitating functional recovery. The tables next to $A-C$ show the statistical comparisons between treatment groups at $42 \mathrm{~d}$ after stroke. Data are shown as mean \pm SEM for $n=8$ per group. ns, No significance. ${ }^{* *} p<0.01,{ }^{* * *} p<0.001$ compared with sham controls; ${ }^{\# \#} p<$ $0.01,{ }^{\#} p<0.001$ compared with stroke plus vehicle-treated animals; $>p<0.001$ compared with stroke plus CX1837-treated animals.

stroke induction. Thus, positive modulation of the AMPAR may affect stroke size, particularly if given early after the stroke. Stroke volume was assessed $7 \mathrm{~d}$ after insult in mice that received stroke plus vehicle or CX1837 at the time of stroke, or beginning $5 \mathrm{~d}$ after stroke, which is the timing of the above studies for effective functional recovery. There was no significant difference in stroke volume between vehicle-treated and CX1837 treatment starting from $5 \mathrm{~d}$ after stroke (stroke plus vehicle, $0.98 \pm 0.13$, vs stroke 
A

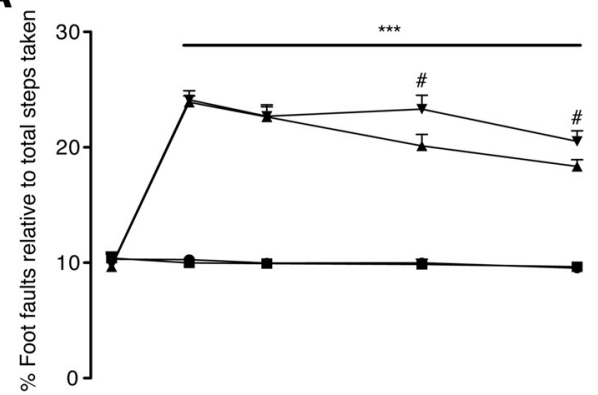

B

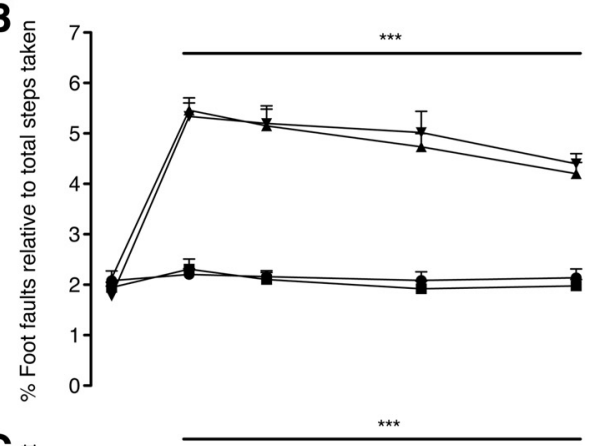

$\mathrm{C}_{\mathrm{z}}$
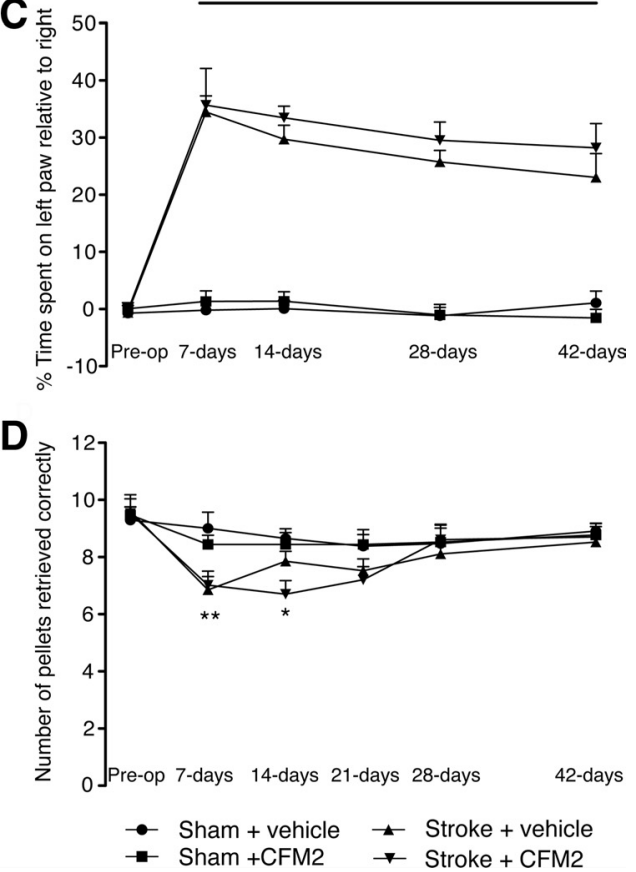

Figure 6. AMPAR antagonism impairs behavioral recovery. Loss of behavioral recovery was assessed after administration of an AMPA receptor selective agonist, CFM2 $(50 \mu \mathrm{mol} / \mathrm{kg})$, on grid-walking $(\boldsymbol{A}, \boldsymbol{B})$, cylinder/forelimb asymmetry $(\boldsymbol{C})$, and reaching $(\boldsymbol{D})$ tasks. Treatment with CFM2 resulted in a significant increase in the number of footfaults on the grid-walking task $(\boldsymbol{A})$ and a decrease in the number of pellets successfully retrieved on the reaching task (D). Data are shown as mean \pm SEM for $n=10$ per group. ${ }^{*} p<0.05,{ }^{* *} p<0.01,{ }^{* * *} p<0.001$ compared with sham controls; ${ }^{\#} p<0.05$ compared with stroke plus vehicle-treated animals.

plus CX1837 late, $1.16 \pm 0.15$ ) (Fig. 9). However, a significant increase in the volume of infarction was seen when treatment with CX1837 started at the time of induction of cerebral ischemia (stroke plus CX1837 early, $1.89 \pm 0.38 ; p<0.05$ ) (Fig. 9).

\section{Discussion}

AMPAR function plays a critical but functionally contradictory role in the spectrum of stroke pathophysiology. AMPAR signaling in the tissue adjacent to the infarct mediates behavioral recovery of limb control over weeks after the stroke. This process occurs through BDNF induction in periinfarct cortex. Positive AMPAR modulation in a way that also induces BDNF promotes improved recovery of motor function during this recovery phase after stroke and blockade of AMPA signaling retards motor recovery. However, immediately after stroke, AMPARs are involved in cell death and infarct evolution. Positive AMPAR modulation increases infarct size immediately after stroke. These data indicate that there is an inflection point within the first several days after stroke where AMPAR signaling switches from promoting cell death to promoting behavioral recovery. Positive modulation of AMPAR signaling during stroke recovery is a novel pharmacological target to promote improved behavioral outcomes in this disease.

\section{Learning and memory and stroke recovery}

Therapies that promote functional recovery after stroke are limited to physical rehabilitation measures, with a limited degree of recovery. There are no pharmacological therapies that stimulate recovery. There are parallels on many levels between mechanisms of learning and memory and those of functional recovery after stroke. Functional recovery after stroke follows psychological learning rules such as learned nonuse, mass action, contextual interference, and distributed practice (Krakauer, 2006) that indicate learning and memory principles may underlie behavioral recovery. On a cellular level, memory formation is mediated by alterations in synaptic strength and structure, including LTP and dendritic spine morphogenesis ((Bliss and Collingridge, 1993). Stroke increases the level of LTP-like cortical excitability (Di Lazzaro et al., 2010) and alters dendritic spine structure (Brown et al., 2007; Sigler et al., 2009). These parallels between learning and memory and stroke recovery suggest that molecular memory systems may play a role in stroke recovery.

AMPAR signaling is one leading candidate for a common memory and stroke recovery system. AMPAR trafficking is important in the induction and maintenance of LTP (Derkach et al., 2007). Increased AMPAR signaling promotes neuronal remodeling and dendritic sprouting that underlies many aspects of learning and memory (Lynch et al., 2008). Here, we report that AMPAR signaling after stroke controls major aspects of motor recovery via an increase in local BDNF levels. We tested the effect of manipulating AMPAR and/or BDNF in two ways. First, we blocked AMPARs with CFM2. This transiently worsened recovery but did not have a generally negative effect on recovery in three different behavioral measures (Fig. 6). We then blocked all of BDNF signaling, by locally releasing TrkB-Fc. This blocked recovery in three measures. These findings disassociate AMPAR effects on recovery from BDNF effects. Blocking BDNF considerably disrupts recovery, indicating that it plays a more fundamental or downstream role on recovery after stroke from the AMPAR. This fits with a model in which positively modulating AMPAR signaling is one way to enhance BDNF effects but that there are likely other mechanisms in place for BDNF induction after stroke.

\section{BDNF and functional recovery in stroke}

BDNF is an activity-dependent trophic factor that mediates many aspects of neuronal plasticity. BDNF mediates neuronal spine plasticity in a process that is thought to underlie LTP (Bramham, 2008; Ji et al., 2010). Additionally, BDNF directly modifies cortical map plasticity (Prakash et al., 1996). Behavioral recovery in 

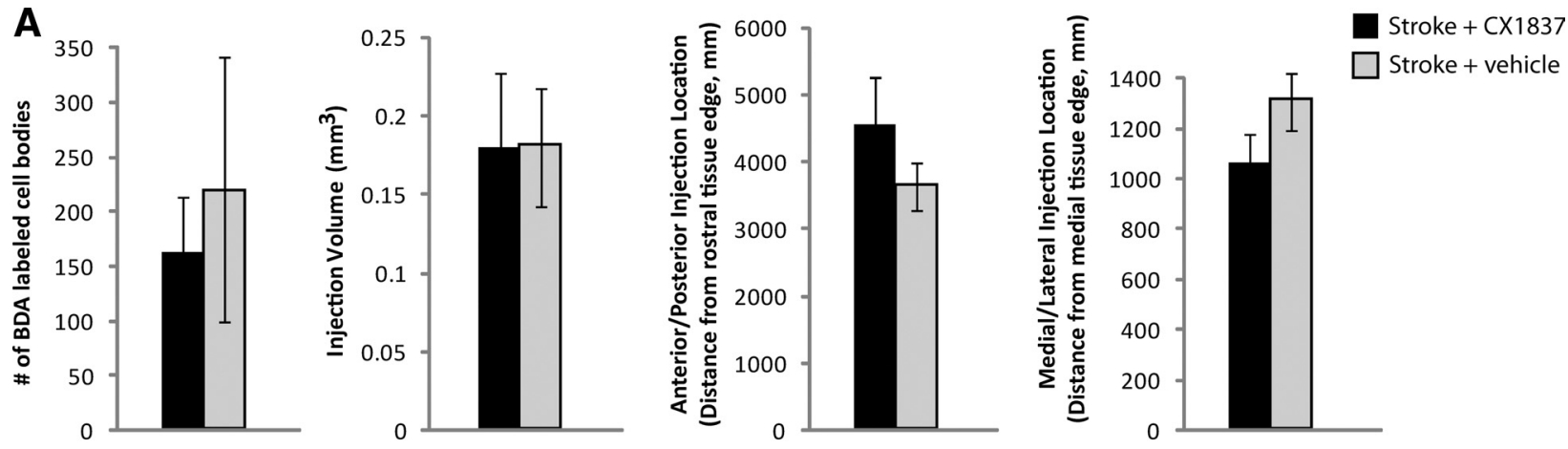

B

Representative injection sites
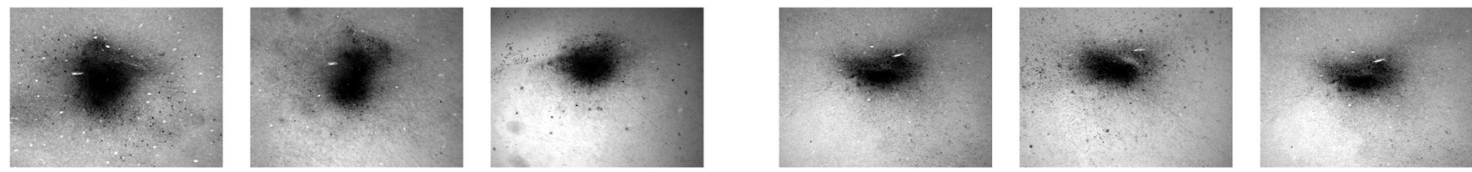

Stroke + CX1837

Stroke + vehicle
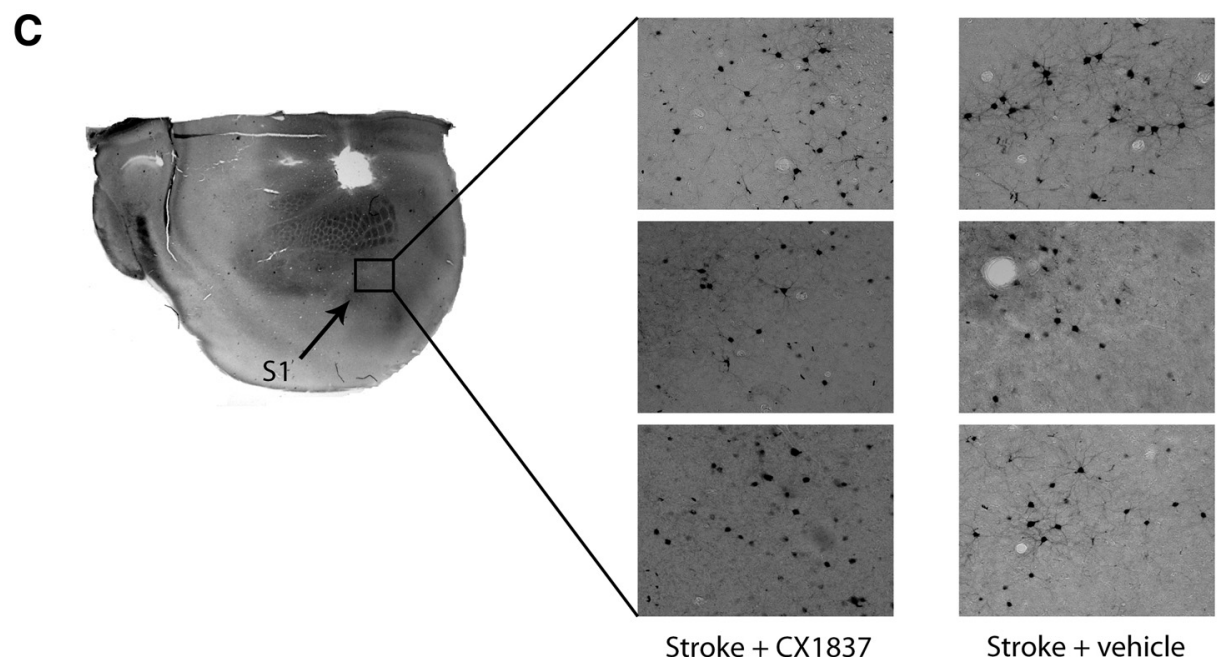

Stroke + vehicle

Figure 7. BDA injection volume and location are uniform across experimental groups. There were no significant differences between the number of BDA-labeled cell bodies, BDA volumes, and location between stroke plus vehicle and stroke plus CX1837-treated animals $(\boldsymbol{A})$. Photomicrographs show representative BDA injection sizes for three animals for stroke plus vehicle and stroke plus CX1837 (B). Sample photomicrographs show representative imaged of BDA-labeled cell bodies in somatosensory cortex (C). Data shown are averages \pm SEM for $n=4$ per group.

stroke is closely correlated with changes in cognitive, motor, and sensory maps. In human stroke patients, an expansion in motor representation maps is seen in tissue adjacent or connected to stroke (Carmichael, 2006). In animal models, when stroke damages primary motor or somatosensory areas, motor and sensory representations remap in periinfarct cortex (Dijkhuizen et al., 2003; Brown et al., 2009), and these map alterations occur in regions of dendritic spine turnover (Brown et al., 2009). These parallels suggest that BDNF may support behavioral recovery after stroke.

The present data show a clear role for BDNF signaling in behavioral recovery after stroke. Systemic administration of CX1837 induces BDNF levels and TrkB phosphorylation in periinfarct cortex. Local blockade of BDNF induction in periinfarct cortex not only prevents the ampakine-mediated behavioral recovery but also generally blocks motor recovery after stroke. Previous studies have shown that intravenous administration of BDNF (Schäbitz et al., 2004) improves behavioral outcome after stroke, and intraventricular infusion of BDNF antisense oligonucleotides (Ploughman et al., 2009) blocks aspects of recovery after stroke. The present data indicate that BDNF normally mediates motor recovery after stroke, localizes this effect to the periinfarct cortex adjacent to the stroke site, and identifies a systemic pharmacological therapy that will modulate BDNF in this critical periinfarct region for motor recovery. BDNF does not appear to induce an improvement in functional recovery through axonal sprouting. These data are the first to specifically localize motor recovery to one brain region after stroke, the periinfarct cortex. Furthermore, because BDNF is poorly permeable to the bloodbrain barrier (Zhang and Pardridge, 2006) and likely to have significant toxicity if given systemically, ampakine administration provides a novel means of inducing BDNF within the periinfarct cortex via a systemic route. 
Brain excitability in neural repair and functional recovery after stroke

The ability to regain function after stroke relies heavily on the ability of the brain to relearn motor and other tasks. This ability to relearn after stroke follows activitydependent processes associated with motor learning and memory (Conner et al., 2005; Krakauer, 2006). As with stroke recovery, the processes of learning and memory can be enhanced by manipulations that increase neuronal excitability (Clarkson and Carmichael, 2009). For example, functional recovery in periinfarct cortex is aided by extrinsic manipulation of neuronal excitability, such as modulation of tonic GABA inhibitory currents (Clarkson et al., 2010). Importantly, the pattern of behavioral recovery induced by blocking tonic GABA currents differs from that seen with positive modulation of AMPAR signaling. Antagonizing tonic GABA inhibition produces an early recovery and rapidly maximal recovery within the first week after stroke (Clarkson et al., 2010). However, positive allosteric modulation of AMPAR function produces a delayed and gradual recovery over 7 weeks (Fig. 1). These data indicate that blocking GABA tonic inhibition and facilitating AMPAR function produce two very different profiles of enhanced recovery, and ones that are specific to each approach.

There are other indications that modulation of cortical excitability impact functional recovery after stroke. Direct current stimulation of periinfarct cortex, using a protocol that boosts local neuronal excitability, improves use of the affected limb in stroke patients (Hummel and Cohen, 2006). Forced use and taskspecific repetitive movements of the affected limb have both been shown to activate the periinfarct cortex and aid in improved functional recovery. A recent report suggests that direct current stimulation may work in part via the enhanced release of BDNF (Cheeran et al., 2008), a mechanism similar to what we find occurs here with the use of high-impact ampakines. The field of direct current stimulation and behavioral brain activation after stroke is evolving, but the cellular mechanisms underlying these therapies are not well understood. However, these data indicate that clinical therapies that alter the excitability of periinfarct cortex, either pharmacological as in the present data or electrical, may improve recovery after stroke and may be comparable with what is described here after treatment with ampakines.

Ampakines have been successfully shown to boost learning and memory function in normal animals, and in genetic models
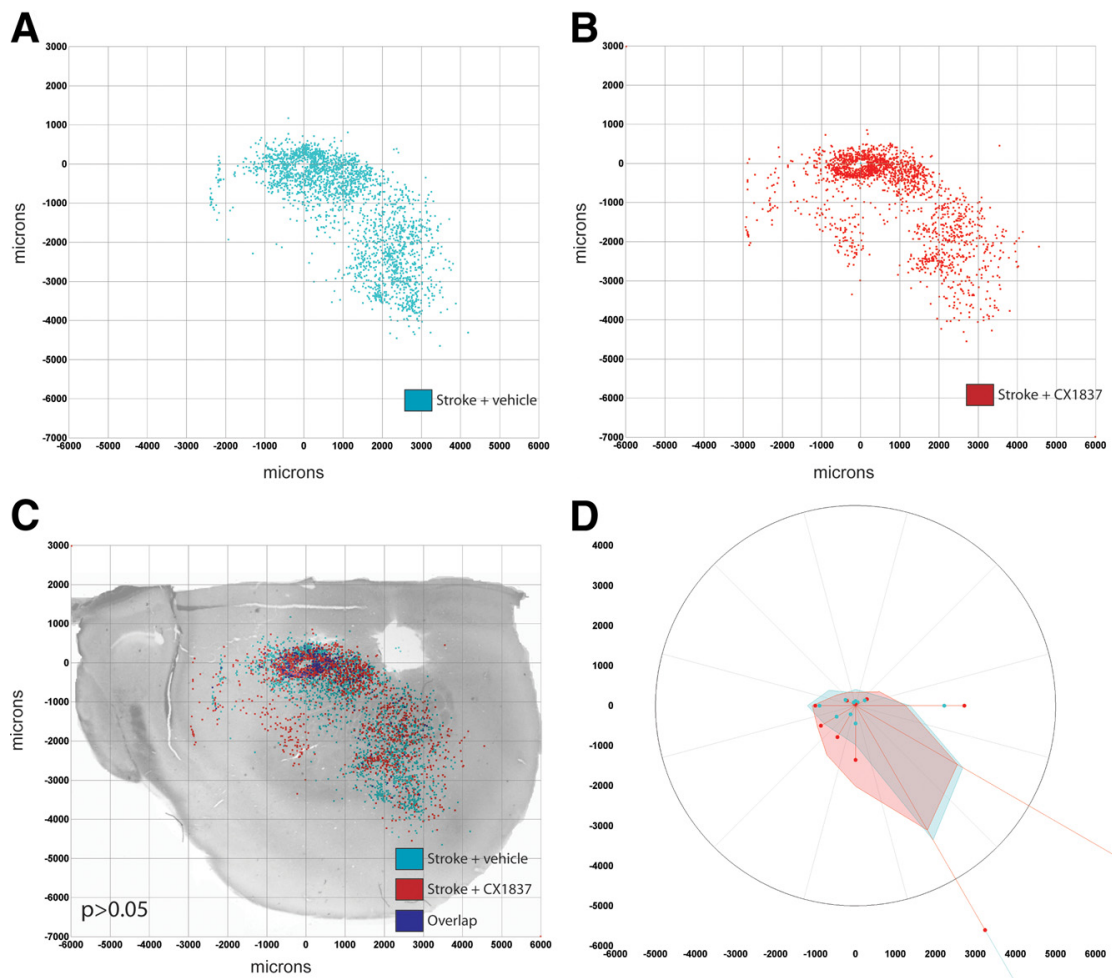

Figure 8. Patterns of cortical connections in control and in conditions of AMPAR conductance. A small injection of the neuroanatomical tracer BDA was placed into the forelimb motor cortex adjacent to the stroke site 6 weeks after stroke. The location of all labeled cell bodies in the forelimb motor cortex, forelimb and hindlimb somatosensory cortex, and facial (whisker) somatosensory cortex were digitally plotted. These plots convert the location of all the axonal connections of forelimb motor cortex into $x / y$ plots, which are then grouped according to treatment condition and statistically compared among groups (Hotelling's inverse $T$ matrix). The plots in $\boldsymbol{A}$ (stroke plus vehicle treatment) and $\boldsymbol{B}$ (stroke plus (X1837 treatment) show the location of labeled axons in groups of animals ( $n=4$ for each condition). For CX1837-treated mice, there is no difference in the spatial distribution ( $C$ relative to vehicle-treated stroke controls. Polar distribution plots, incorporating normalized axon quantity and distribution of axons in register with connectional plot $(\boldsymbol{D})$. Shaded polygons $(\boldsymbol{D})$ represent 70th percentile of the distances of labeled axons from the injection site in each segment of the graph.

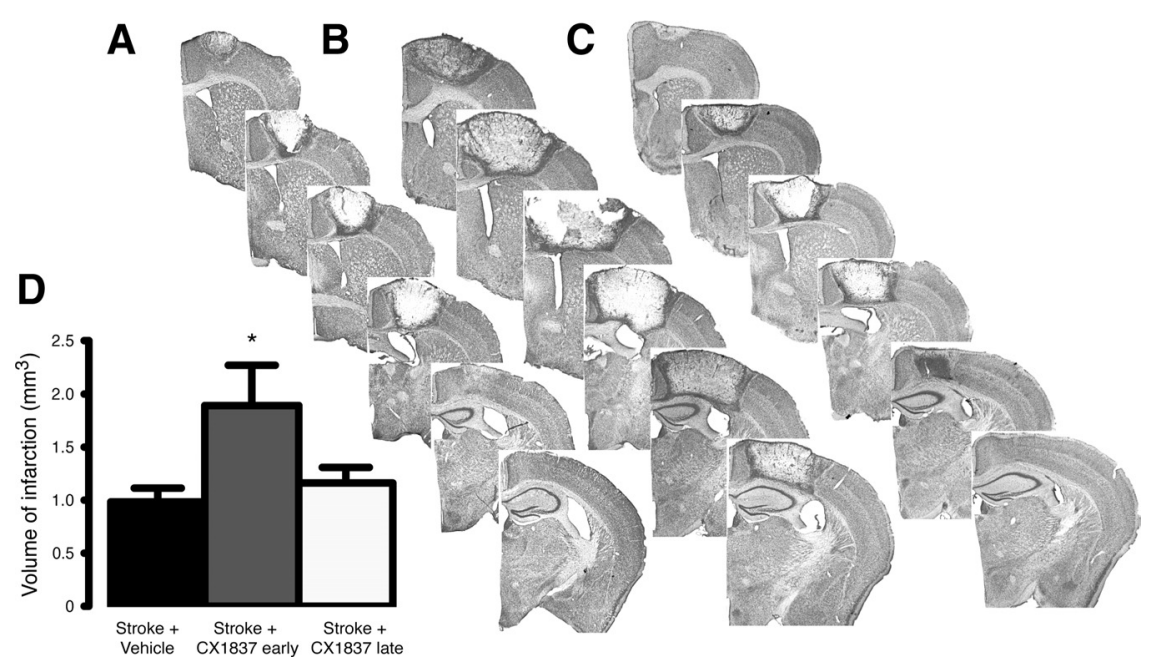

Figure 9. Inflection point in CX1837 effect on infarct size. Representative Nissl-stained sections $7 \mathrm{~d}$ after stroke from stroke plus vehicle treatment $(\boldsymbol{A})$, stroke plus $(X 1837$ treatment starting at the time of stroke $(\boldsymbol{B})$, and stroke plus CX1837 treatment starting from $5 \mathrm{~d}$ after insult (C). Quantification of the stroke volume is shown in $\boldsymbol{D}$. Data are shown as mean \pm SEM for $n=4$ per group. ${ }^{*} p<0.05$.

of cognitive diseases, such as Huntington's disease (Simmons et al., 2009). We show for the first time that the BDNF-inducing ampakine CX1837 boosts motor recovery after stroke. This suggests that the similarities between neuronal mechanisms of learning and memory and those of functional recovery after stroke 
may extend more generally to common treatment strategies for both. Initial cell death and delayed neuronal recovery both occur through overlapping excitatory mechanisms. An important point from the present studies is that treatments that focus on manipulating molecular memory systems to alter excitatory signaling and recovery in the brain must be accomplished at specific delay points after the onset of stroke.

\section{References}

Arai AC, Kessler M (2007) Pharmacology of ampakine modulators: from AMPA receptors to synapses and behavior. Curr Drug Targets 8:583-602.

Batchelor PE, Wills TE, Hewa AP, Porritt MJ, Howells DW (2008) Stimulation of axonal sprouting by trophic factors immobilized within the wound core. Brain Res 1209:49-56.

Bliss TV, Collingridge GL (1993) A synaptic model of memory: long-term potentiation in the hippocampus. Nature 361:31-39.

Bramham CR (2008) Local protein synthesis, actin dynamics, and LTP consolidation. Curr Opin Neurobiol 18:524-531.

Braun JS, Jander S, Schroeter M, Witte OW, Stoll G (1996) Spatiotemporal relationship of apoptotic cell death to lymphomonocytic infiltration in photochemically induced focal ischemia of the rat cerebral cortex. Acta Neuropathol 92:255-263.

Brown CE, Li P, Boyd JD, Delaney KR, Murphy TH (2007) Extensive turnover of dendritic spines and vascular remodeling in cortical tissues recovering from stroke. J Neurosci 27:4101-4109.

Brown CE, Aminoltejari K, Erb H, Winship IR, Murphy TH (2009) In vivo voltage-sensitive dye imaging in adult mice reveals that somatosensory maps lost to stroke are replaced over weeks by new structural and functional circuits with prolonged modes of activation within both the periinfarct zone and distant sites. J Neurosci 29:1719-1734.

Bütefisch CM, Kleiser R, Seitz RJ (2006) Post-lesional cerebral reorganisation: evidence from functional neuroimaging and transcranial magnetic stimulation. J Physiol Paris 99:437-454.

Carmichael ST (2006) Cellular and molecular mechanisms of neural repair after stroke: making waves. Ann Neurol 59:735-742.

Carmichael ST, Wei L, Rovainen CM, Woolsey TA (2001) New patterns of intracortical projections after focal cortical stroke. Neurobiol Dis 8:910-922.

Cheeran B, Talelli P, Mori F, Koch G, Suppa A, Edwards M, Houlden H, Bhatia K, Greenwood R, Rothwell JC (2008) A common polymorphism in the brain-derived neurotrophic factor gene (BDNF) modulates human cortical plasticity and the response to rTMS. J Physiol 586:5717-5725.

Clarkson AN, Carmichael ST (2009) Cortical excitability and post-stroke recovery. Biochem Soc Trans 37:1412-1414.

Clarkson AN, Huang BS, Macisaac SE, Mody I, Carmichael ST (2010) Reducing excessive GABA-mediated tonic inhibition promotes functional recovery after stroke. Nature 468:305-309.

Conner JM, Chiba AA, Tuszynski MH (2005) The basal forebrain cholinergic system is essential for cortical plasticity and functional recovery following brain injury. Neuron 46:173-179.

Dancause N, Barbay S, Frost SB, Plautz EJ, Chen D, Zoubina EV, Stowe AM, Nudo RJ (2005) Extensive cortical rewiring after brain injury. J Neurosci 25:10167-10179.

Derkach VA, Oh MC, Guire ES, Soderling TR (2007) Regulatory mechanisms of AMPA receptors in synaptic plasticity. Nat Rev Neurosci 8:101-113.

De Sarro G, Di Paola ED, Gareri P, Gallelli L, Scotto G, De Sarro A (1999) Effects of some AMPA receptor antagonists on the development of tolerance in epilepsy-prone rats and in pentylenetetrazole kindled rats. Eur J Pharmacol 368:149-159.

Dijkhuizen RM, Singhal AB, Mandeville JB, Wu O, Halpern EF, Finklestein SP, Rosen BR, Lo EH (2003) Correlation between brain reorganization, ischemic damage, and neurologic status after transient focal cerebral ischemia in rats: a functional magnetic resonance imaging study. J Neurosci 23:510-517.

Di Lazzaro V, Profice P, Pilato F, Capone F, Ranieri F, Pasqualetti P, Colosimo C, Pravatà E, Cianfoni A, Dileone M (2010) Motor cortex plasticity predicts recovery in acute stroke. Cereb Cortex 20:1523-1528.

Dobkin BH (2004) Strategies for stroke rehabilitation. Lancet Neurol 3:528-536.
Dobkin BH (2008) Training and exercise to drive poststroke recovery. Nat Clin Pract Neurol 4:76-85.

Goff DC, Lamberti JS, Leon AC, Green MF, Miller AL, Patel J, Manschreck T, Freudenreich O, Johnson SA (2008) A placebo-controlled add-on trial of the Ampakine, CX516, for cognitive deficits in schizophrenia. Neuropsychopharmacology 33:465-472.

Hagemann G, Redecker C, Neumann-Haefelin T, Freund HJ, Witte OW (1998) Increased long-term potentiation in the surround of experimentally induced focal cortical infarction. Ann Neurol 44:255-258.

Hampson RE, Rogers G, Lynch G, Deadwyler SA (1998) Facilitative effects of the ampakine CX516 on short-term memory in rats: correlations with hippocampal neuronal activity. J Neurosci 18:2748-2763.

Hummel FC, Cohen LG (2006) Non-invasive brain stimulation: a new strategy to improve neurorehabilitation after stroke? Lancet Neurol 5:708-712.

Ji Y, Lu Y, Yang F, Shen W, Tang TT, Feng L, Duan S, Lu B (2010) Acute and gradual increases in BDNF concentration elicit distinct signaling and functions in neurons. Nat Neurosci 13:302-309.

Jourdi H, Hsu YT, Zhou M, Qin Q, Bi X, Baudry M (2009) Positive AMPA receptor modulation rapidly stimulates BDNF release and increases dendritic mRNA translation. J Neurosci 29:8688-8697.

Kelly C, Foxe JJ, Garavan H (2006) Patterns of normal human brain plasticity after practice and their implications for neurorehabilitation. Arch Phys Med Rehabil 87:S20-S29.

Krakauer JW (2006) Motor learning: its relevance to stroke recovery and neurorehabilitation. Curr Opin Neurol 19:84-90.

Lauterborn JC, Truong GS, Baudry M, Bi X, Lynch G, Gall CM (2003) Chronic elevation of brain-derived neurotrophic factor by ampakines. J Pharmacol Exp Ther 307:297-305.

Lauterborn JC, Pineda E, Chen LY, Ramirez EA, Lynch G, Gall CM (2009) Ampakines cause sustained increases in brain-derived neurotrophic factor signaling at excitatory synapses without changes in AMPA receptor subunit expression. Neuroscience 159:283-295.

Li S, Overman JJ, Katsman D, Kozlov SV, Donnelly CJ, Twiss JL, Giger RJ, Coppola G, Geschwind DH, Carmichael ST (2010) An age-related sprouting transcriptome provides molecular control of axonal sprouting after stroke. Nat Neurosci 13:1496-1504.

Lipton P (1999) Ischemic cell death in brain neurons. Physiol Rev 79: $1431-1568$

Lynch G, Rex CS, Chen LY, Gall CM (2008) The substrates of memory: defects, treatments, and enhancement. Eur J Pharmacol 585:2-13.

Ohab JJ, Fleming S, Blesch A, Carmichael ST (2006) A neurovascular niche for neurogenesis after stroke. J Neurosci 26:13007-13016.

Ploughman M, Windle V, MacLellan CL, White N, Doré JJ, Corbett D (2009) Brain-derived neurotrophic factor contributes to recovery of skilled reaching after focal ischemia in rats. Stroke 40:1490-1495.

Prakash N, Cohen-Cory S, Frostig RD (1996) RAPID and opposite effects of BDNF and NGF on the functional organization of the adult cortex in vivo. Nature 381:702-706

Rex CS, Lauterborn JC, Lin CY, Kramár EA, Rogers GA, Gall CM, Lynch G (2006) Restoration of long-term potentiation in middle-aged hippocampus after induction of brain-derived neurotrophic factor. J Neurophysiol 96:677-685.

Schäbitz WR, Berger C, Kollmar R, Seitz M, Tanay E, Kiessling M, Schwab S, Sommer C (2004) Effect of brain-derived neurotrophic factor treatment and forced arm use on functional motor recovery after small cortical ischemia. Stroke 35:992-997.

Sigler A, Mohajerani MH, Murphy TH (2009) Imaging rapid redistribution of sensory-evoked depolarization through existing cortical pathways after targeted stroke in mice. Proc Natl Acad Sci U S A 106:11759-11764.

Simmons DA, Rex CS, Palmer L, Pandyarajan V, Fedulov V, Gall CM, Lynch G (2009) Up-regulating BDNF with an ampakine rescues synaptic plasticity and memory in Huntington's disease knockin mice. Proc Natl Acad Sci U S A 106:4906-4911.

Weiser T (2005) AMPA receptor antagonists for the treatment of stroke. Curr Drug Targets CNS Neurol Disord 4:153-159.

Zhang Y, Pardridge WM (2006) Blood-brain barrier targeting of BDNF improves motor function in rats with middle cerebral artery occlusion. Brain Res 1111:227-229. 